Article

\title{
Methanol Reforming over Cobalt Catalysts Prepared from Fumarate Precursors: TPD Investigation
}

\author{
Eftichia Papadopoulou and Theophilos Ioannides *
}

Foundation for Research and Technology-Hellas (FORTH), Institute of Chemical Engineering Sciences (ICE-HT), Stadiou str., Platani, GR-26504 Patras, Greece; epapado@iceht.forth.gr

* Correspondence: theo@iceht.forth.gr; Tel.: +30-2610-965-264; Fax: +30-2610-965-223

Academic Editor: Michalis Konsolakis

Received: 30 November 2015; Accepted: 16 February 2016; Published: 24 February 2016

\begin{abstract}
Temperature-programmed desorption (TPD) was employed to investigate adsorption characteristics of $\mathrm{CH}_{3} \mathrm{OH}, \mathrm{H}_{2} \mathrm{O}, \mathrm{H}_{2}, \mathrm{CO}_{2}$ and $\mathrm{CO}$ on cobalt-manganese oxide catalysts prepared through mixed Co-Mn fumarate precursors either by pyrolysis or oxidation and oxidation/reduction pretreatment. Pyrolysis temperature and $\mathrm{Co} / \mathrm{Mn}$ ratio were the variable synthesis parameters. Adsorption of methanol, water and $\mathrm{CO}_{2}$ was carried out at room temperature. Adsorption of $\mathrm{H}_{2}$ and $\mathrm{H}_{2} \mathrm{O}$ was carried out at 25 and $300{ }^{\circ} \mathrm{C}$. Adsorption of $\mathrm{CO}$ was carried out at 25 and $150{ }^{\circ} \mathrm{C}$. The goal of the work was to gain insight on the observed differences in the performance of the aforementioned catalysts in methanol steam reforming. TPD results indicated that activity differences are mostly related to variation in the number density of active sites, which are able to adsorb and decompose methanol.
\end{abstract}

Keywords: adsorption; cobalt; manganese; TPD; $\mathrm{CO} ; \mathrm{CO}_{2} ; \mathrm{H}_{2} ; \mathrm{H}_{2} \mathrm{O} ; \mathrm{CH}_{3} \mathrm{OH}$

\section{Introduction}

Mixed cobalt-manganese fumarate salts are useful precursors leading to catalysts with different structure depending on the type of surrounding atmosphere during activation [1]. Thus, activation in air leads to burn-off of the fumarate group and concomitant formation of mixed $\mathrm{Co}_{x} \mathrm{Mn}_{1-x} \mathrm{O}_{y}$ spinel oxides, while activation in inert gas leads to pyrolysis of the fumarate group and formation of species with lower oxidation state, such as metallic cobalt, mixed oxides of $\mathrm{Co}^{2+}$ and $\mathrm{Mn}^{2+}$ and residual carbon. Combination of in-situ XRD, $\mathrm{H}_{2}$-TPR and methanol-TPR has shown that catalysts produced by pyrolysis are almost fully reduced [1]. Thus, catalysts derived from pyrolysis do not need prereduction and are more active than those with an initial spinel structure in the reaction of steam reforming of ethanol or methanol [2]. State-of-the-art catalysts for steam reforming of methanol are copper-based and operate at $250-300{ }^{\circ} \mathrm{C}$, while ethanol reforming requires higher temperatures of the order of $600^{\circ} \mathrm{C}$ [3-9]. Cobalt is a less efficient catalyst than copper in the steam reforming of methanol operating at temperatures around $400{ }^{\circ} \mathrm{C}$ [2].

From a mechanistic point of view, adsorption is a key step in catalytic reactions. Hence, study of adsorption and desorption of relevant molecules on catalytic surfaces can provide insight on the population and intrinsic properties of active sites. TPD, in particular, is a standard technique via which one can obtain information concerning: (i) adsorption site homogeneity, as reflected in the presence of one or more desorption peaks; (ii) strength of the adsorbate-surface bond, as reflected in the peak temperature of desorbed species; and (iii) number density of adsorption sites, as reflected in the amount of desorbed species. It is especially useful in comparative parametric studies of a catalyst family.

Adsorption of methanol on a $\mathrm{Co}(0001)$ surface takes place as methoxide via $\mathrm{OH}$ bond scission. During heating, a small amount of methanol desorbs molecularly, while the majority of methoxide 
decomposes to $\mathrm{CO}$ and hydrogen [10]. Infrared spectra produced by adsorbed species formed during the exposure of silica-supported Co to methanol have been obtained by Bliholder et al. [11]. Methanol was found to adsorb to a small extent on the silica support -probably as a methoxide, while varying mixtures of methoxide, acyl, and chemisorbed $\mathrm{CO}$ species were produced on $\mathrm{Co}$. The interaction between $\mathrm{Co}_{3} \mathrm{O}_{4}$ or $\mathrm{CoO}$ with methanol under either atmospheric or high vacuum conditions was examined by Natile et al. [12]. Methanol was found to chemisorb mainly molecularly on cobalt oxide surfaces, while its dissociation became evident at higher temperatures. In the case of $\mathrm{Co}_{3} \mathrm{O}_{4}$, the presence of formate and formaldehyde species was evident in the temperature range $200-350{ }^{\circ} \mathrm{C}$, whereas under high vacuum conditions, formaldehyde and several decomposition and fragmentation products were observed along with carbon oxides.

Adsorption of water on a hexagonal Co(1120) surface was studied by means of photoelectron spectroscopies (XPS, UPS) by Grellner et al. [13]. Molecular adsorption of water at $100 \mathrm{~K}$ was accompanied by the formation of small amounts of $\mathrm{OH}$ in the submonolayer range. When the temperature is increased, desorption of the multilayer occurs first at $150 \mathrm{~K}$ and $\mathrm{OH}$ remains on the surface. Disproportionation of $\mathrm{OH}$ takes place at $270 \mathrm{~K}$ leaving oxygen on the surface. A systematic study of the adsorption and dissociation of water on transition and noble metal dimers was presented by Heras et al. [14].

Activated hydrogen chemisorption on unsupported and supported (silica, alumina, titania, magnesia, and carbon supports) cobalt catalysts prepared by a variety of techniques has been reported by Bartholomew et al. [15-17]. The surface interaction of $\mathrm{CO}, \mathrm{CO}_{2}$ and $\mathrm{H}_{2}$ with the perovskite-type oxide $\mathrm{LaCoO}_{x}$ has been studied as a function of reduction temperature using XPS and TPD by Tejuca et al. [18]. Hydrogen was found to adsorb on cobalt both weakly and strongly (desorption peaks at $70{ }^{\circ} \mathrm{C}$ and above $200{ }^{\circ} \mathrm{C}$ ). Dissociative adsorption yielding hydroxyl groups was also detected. Narayanan et al. [19] studied $\mathrm{H}_{2}$ adsorption at $100{ }^{\circ} \mathrm{C}$ on $\mathrm{Co} / \mathrm{Al}_{2} \mathrm{O}_{3}$ catalysts with varying cobalt content $(10 \%-50 \%)$. The amount of adsorbed $\mathrm{H}_{2}$ was $15 \mu \mathrm{mol} \cdot \mathrm{g}^{-1}$ at $20 \%$ cobalt loading and increased to $67 \mu \mathrm{mol} \cdot \mathrm{g}^{-1}$ for $50 \%$ cobalt loading. Hydrogen adsorption/desorption characteristics on Co-TiN nanocomposite particles have been studied using TPD by Sakka et al. [20]. Hydrogen desorption was observed in the temperature range $100-320^{\circ} \mathrm{C}$. Activated chemisorption of hydrogen on prereduced $\mathrm{MnFe}_{2} \mathrm{O}_{4}$ spinel oxides was reported by Soong et al. [21]. Hydrogen desorption at $570-630{ }^{\circ} \mathrm{C}$ was attributed to chemisorbed species on $\mathrm{MnO}$.

Gauthier et al. [22] investigated CO adsorption on $\mathrm{PtCo}(111)$ surfaces by scanning tunneling microscopy. It was found that $\mathrm{CO}$ molecules reside exclusively on top of Pt sites and never on Co. High-pressure, in-situ diffuse reflectance, Fourier Transform Infrared Spectroscopy was employed by Jiang et al. [23] to study CO adsorption on samples derived from precipitated cobalt-manganese oxides of different $\mathrm{Co} / \mathrm{Mn}$ ratios reduced by $\mathrm{H}_{2}$. According to their results the adsorption features of the samples vary significantly with manganese loading. CO linearly adsorbed, bridged and multiple-bridged on $\mathrm{Co}^{\circ}$ sites was identified. Mohana et al. [24] found that $\mathrm{CO}$ adsorption at room temperature on cobalt particles supported on $\mathrm{MgO}$ leads mainly to the formation of linearly adsorbed species, while the disproportionation reaction accompanied by carbon deposition already takes place at room temperature. Carbon deposition on cobalt catalysts in Fischer-Tropsch and steam reforming reactions is well-documented [25-31]. Regarding methanol reforming, the pathway of carbon deposition on cobalt catalysts appears to be the Boudouard reaction since $\mathrm{CO}$ is the main reaction product. The structure of carbon deposits originating from $\mathrm{CO}$ depends on reaction temperature with amorphous and filamentous carbon prevailing at low temperatures $\left(350-600{ }^{\circ} \mathrm{C}\right)$, which are relevant to methanol steam reforming [31]. Formation of filamentous carbon does not lead to catalyst deactivation but rather to reactor plugging leading to excessive pressure drop.

In the present study, TPD experiments of pre-adsorbed $\mathrm{CH}_{3} \mathrm{OH}, \mathrm{H}_{2} \mathrm{O}, \mathrm{H}_{2}, \mathrm{CO}_{2}$ and $\mathrm{CO}$ were employed in order to examine the adsorptive properties of cobalt catalysts prepared through mixed cobalt-manganese fumarate precursors by activation under oxidative or reducing conditions. The objective of this study was to investigate the effect of catalyst synthesis parameters on the 
corresponding adsorptive properties. More specifically, the examined catalyst synthesis parameters were: (i) the activation type, pyrolysis or calcination; (ii) the $\mathrm{Co} / \mathrm{Mn}$ ratio; and (iii) the pyrolysis temperature. These are the main parameters influencing the structure [1] and activity [2] of the specific catalysts in methanol steam reforming. To our knowledge, an extensive investigation of the adsorption of a variety of catalysis relevant molecules on Co-Mn based catalysts has not been reported previously.

\section{Results and Discussion}

\subsection{TPD of Adsorbed $\mathrm{CO}$ or $\mathrm{CO}_{2}$}

No significant $\mathrm{CO}$ adsorption was found on the catalysts (both pyrolyzed and preoxidized ones) following exposure to $\mathrm{CO}$ at room temperature. As an example, TPD results following $\mathrm{CO}$ adsorption on the CoMn11AFp600 catalyst at 25 and $150{ }^{\circ} \mathrm{C}$ are presented in Figure 1a,b. The curve called "blank" corresponds to the amounts of $\mathrm{CO}$ and $\mathrm{CO}_{2}$ observed during TPD without any prior $\mathrm{CO}$ adsorption. $\mathrm{CO}$ and $\mathrm{CO}_{2}$ production in the blank experiment is due to residual decomposition of organic species originating from the fumarate precursor. It can be observed that after adsorption of $\mathrm{CO}$ at room temperature, there is minimal desorption of CO during TPD (less than $20 \mathrm{ppm}$ of $\mathrm{CO}$ in the gaseous stream) and no $\mathrm{CO}_{2}$ desorption. Following $\mathrm{CO}$ adsorption at $150^{\circ} \mathrm{C}$, both $\mathrm{CO}$ and $\mathrm{CO}_{2}$ were found in the TPD profile. $\mathrm{CO}$ desorbs in the form of two peaks at $50{ }^{\circ} \mathrm{C}$ and $140{ }^{\circ} \mathrm{C}$, while $\mathrm{CO}_{2}$ appears with a main peak at $200{ }^{\circ} \mathrm{C}$ followed by a shoulder at $350{ }^{\circ} \mathrm{C}$ and a smaller peak at $500{ }^{\circ} \mathrm{C}$. The origin of $\mathrm{CO}_{2}$ could be either the Boudouard reaction or oxidation of adsorbed $\mathrm{CO}$ by surface oxygen. Based on literature findings, the occurrence of the Boudouard reaction is highly probable. For example, formation of carbon on a $\mathrm{Co} / \mathrm{Al}_{2} \mathrm{O}_{3}$ catalyst by $\mathrm{CO}$ disproportionation at $230{ }^{\circ} \mathrm{C}$ has been reported by Nakamura et al. [32]. This temperature is in the same range as the one shown in Figure $1 \mathrm{~b}$ regarding $\mathrm{CO}_{2}$ formation. $\mathrm{CO}$ disproportionation on $\mathrm{Co} / \mathrm{MgO}$ catalysts has been found to take place already at room temperature [24]. Since the catalyst samples of this work, however, contain carbon in their composition (residual carbon from fumarate pyrolysis), it is not possible to measure any carbon formed on the catalysts from $\mathrm{CO}$ disproportionation via subsequent temperature-programmed oxidation.

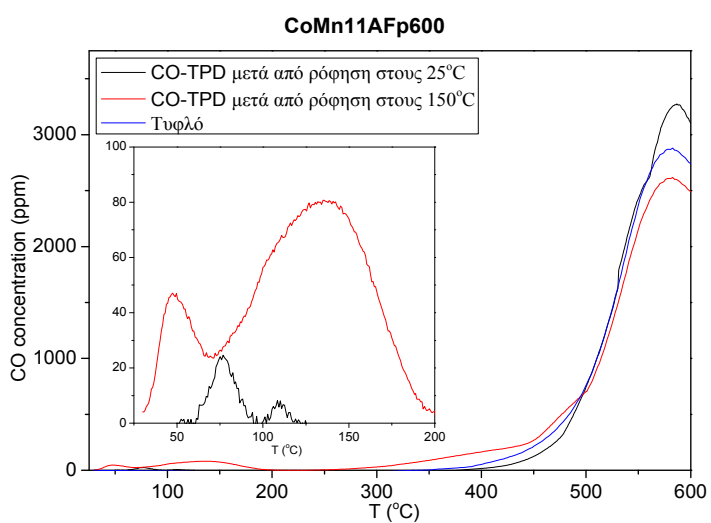

(a)

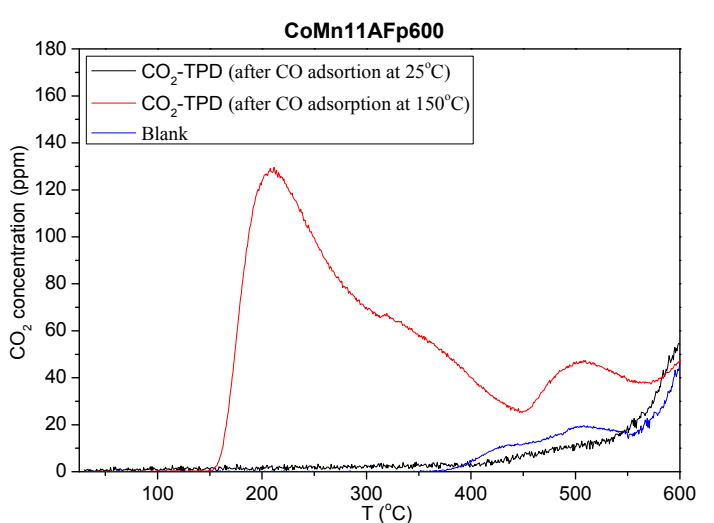

(b)

Figure 1. TPD following $\mathrm{CO}$ adsorption at $25^{\circ} \mathrm{C}$ or $150{ }^{\circ} \mathrm{C}$ on CoMn11AFp600 catalyst: (a) CO desorption; and (b) $\mathrm{CO}_{2}$ desorption.

The corresponding results of TPD following $\mathrm{CO}_{2}$ adsorption at $25^{\circ} \mathrm{C}$ on catalysts prepared via oxidation and oxidation/reduction or pyrolysis are given in Figure $2 \mathrm{a}, \mathrm{b}$, respectively. $\mathrm{CO}_{2}$ profiles from oxidized/reduced catalysts (Figure 2a) show a main peak at $\sim 100^{\circ} \mathrm{C}$ and a smaller high temperature peak above $500{ }^{\circ} \mathrm{C} . \mathrm{CO}_{2}$ profiles from pyrolyzed catalysts are quite complicated and broad from 30 to $600{ }^{\circ} \mathrm{C}$ with multiple desorption peaks. The population of sites that adsorb $\mathrm{CO}_{2}$ strongly appears to decrease with increase of pyrolysis temperature and this leads to concomitant decrease of the amount of desorbed $\mathrm{CO}_{2}$ with increase of pyrolysis temperature. More specifically, the amount 
of desorbed $\mathrm{CO}_{2}$ is $240 \mu \mathrm{mol} \cdot \mathrm{g}^{-1}$ for CoMn11AFp500 and decreases to 100 and $57 \mu \mathrm{mol} \cdot \mathrm{g}^{-1}$ for catalysts prepared by pyrolysis at 600 and $700{ }^{\circ} \mathrm{C}$, respectively. At the same time, the specific surface area of pyrolyzed samples is more or less independent of pyrolysis temperature in the range of 200-220 $\mathrm{m}^{2} \cdot \mathrm{g}^{-1}$, as measured by the BET method. This indicates that pyrolysis temperature affects mostly active sites for adsorption of $\mathrm{CO}_{2}$ and not the exposed surface area in general. The amount of adsorbed $\mathrm{CO}_{2}$ on catalysts prepared by oxidation/reduction is $17-19 \mu \mathrm{mol} \cdot \mathrm{g}^{-1}$, i.e., considerably smaller than the one found over the pyrolyzed catalysts. This is in line with the smaller specific surface area of these samples by one order of magnitude.

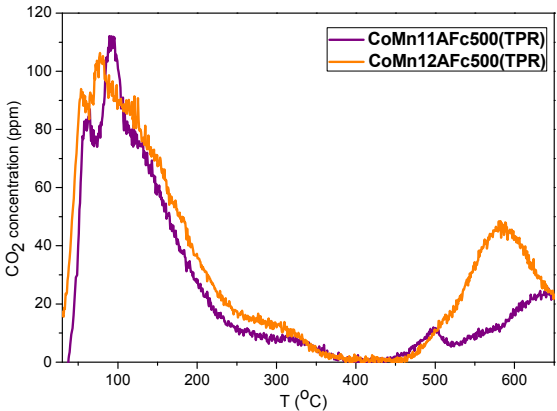

(a)

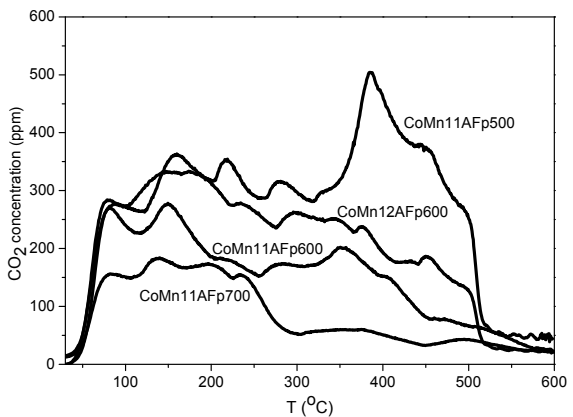

(b)

Figure 2. TPD of $\mathrm{CO}_{2}$ following its adsorption at $25^{\circ} \mathrm{C}$ on (a) $\mathrm{CoMn} 1 x \mathrm{AFc} 500$ (TPR), $x=1,2$; and (b) CoMn11AFpi, $i=500,600,700{ }^{\circ} \mathrm{C}$ and CoMn12AFp600.

\subsection{TPD of Adsorbed $\mathrm{H}_{2}$}

$\mathrm{H}_{2}$-TPD studies were carried out following $\mathrm{H}_{2}$ adsorption at 25 or $300{ }^{\circ} \mathrm{C}$ under a flow of pure hydrogen. Representative TPD profiles of hydrogen are presented in Figure 3. The oxidized/reduced sample (CoMn11AFc500(TPR)) adsorbed no measurable amount of hydrogen at room temperature and trace amounts at $300^{\circ} \mathrm{C}$. The pyrolyzed cobalt-only sample indicates the presence of rather weakly bound hydrogen desorbing with peak at $\sim 70^{\circ} \mathrm{C}$. Increase of adsorption temperature to $300^{\circ} \mathrm{C}$ leads to population of more strongly-bound adsorbed hydrogen, as evidenced by the appearance of a shoulder at $100-200{ }^{\circ} \mathrm{C}$. TPD profiles from the manganese-only sample show the presence of strongly-bound hydrogen desorbing in the range of $400-650{ }^{\circ} \mathrm{C}$ after adsorption at room temperature. Increase of adsorption temperature to $300{ }^{\circ} \mathrm{C}$ leads to the appearance of an intermediate-strength state with desorption at $\sim 300{ }^{\circ} \mathrm{C}$. The TPD profile from the CoMn11AFp600 sample, which contains both cobalt and manganese, incorporates features that are attributable to the presence of both cobalt crystallites and $\mathrm{MnO}$. Strongly-bound hydrogen desorbs at $460^{\circ} \mathrm{C}$ and is larger in quantity compared to the manganese-only sample. Therefore, the observed profile is not just the sum of isolated contributions of cobalt and $\mathrm{MnO}$ species, but is influenced by mutual interactions. Table 1 presents the amounts of desorbed hydrogen during TPD after adsorption at 25 and $300{ }^{\circ} \mathrm{C}$. The oxidized catalyst which had been reduced prior to $\mathrm{H} 2$ adsorption adsorbs no $\mathrm{H}_{2}$ at room temperature and $10 \mu \mathrm{mol} \cdot \mathrm{g}^{-1}$ at $300{ }^{\circ} \mathrm{C}$, which is one to two orders of magnitude smaller than the corresponding values of catalysts from the same precursor prepared by pyrolysis. Concerning the effect of adsorption temperature, it is observed that the amount of desorbed hydrogen increases by up to $350 \%$ with increase of adsorption temperature from 25 to $300{ }^{\circ} \mathrm{C}$. The smallest increase is found for the sample adsorbing the largest amount of hydrogen at room temperature, i.e., CoMn11AFp600. The amounts of desorbed hydrogen in samples containing both cobalt and manganese are considerably larger than the ones found over single-component samples, indicating the presence of synergy and creation of additional adsorption sites. Contrary to what was found in the case of $\mathrm{CO}_{2}$ adsorption, the amount of adsorbed hydrogen does not decrease with increase of pyrolysis temperature, indicating that at least some of the adsorption sites for hydrogen and $\mathrm{CO}_{2}$ are not identical. Using the data in Table 1, estimates of the maximum 
dispersion of cobalt in the various catalysts can be provided assuming that no adsorption takes place on $\mathrm{MnO}$ sites in the case of Co-Mn catalysts. Taking that the stoichiometry of hydrogen adsorption is one hydrogen atom per one surface cobalt atom, the dispersion $(\mathrm{H} / \mathrm{Co})$ ratio is $\sim 2 \%$ for the cobalt-only catalyst and becomes even higher than $20 \%$ for Co-Mn catalysts pyrolyzed at $600{ }^{\circ} \mathrm{C}$.

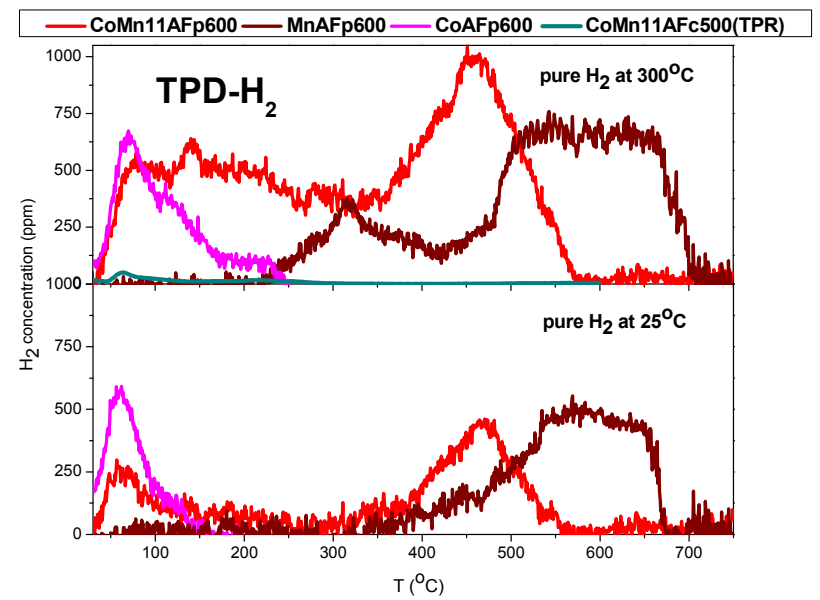

Figure 3. $\mathrm{H}_{2}$-TPD profiles following its adsorption at $25^{\circ} \mathrm{C}$ and $300^{\circ} \mathrm{C}$ on CoMn11AFp600, CoAFp600, MnAFp600 and CoMn11AFc500 (TPR) samples.

Table 1. Amounts of hydrogen desorbed during TPD after adsorption at 25 and $300{ }^{\circ} \mathrm{C}$.

\begin{tabular}{|c|c|c|c|c|}
\hline \multirow{2}{*}{ Catalyst } & \multicolumn{2}{|c|}{$\mathrm{H}_{2}$-TPD Adsorption at $25^{\circ} \mathrm{C}$} & \multicolumn{2}{|c|}{$\mathrm{H}_{2}$-TPD Adsorption at $300{ }^{\circ} \mathrm{C}$} \\
\hline & $\mu \mathrm{mol} \mathrm{H}_{2} \mathrm{~g}^{-1}$ & H/Co & $\mu \mathrm{mol} \mathrm{H} \mathrm{H}^{-1}$ & H/Co \\
\hline CoMn11AFp500 & 174 & 0.058 & 492 & 0.164 \\
\hline CoMn11AFp600 & 189 & 0.060 & 661 & 0.210 \\
\hline CoMn11AFp700 & 328 & 0.104 & 371 & 0.118 \\
\hline CoMn12AFp600 & 195 & 0.096 & 478 & 0.236 \\
\hline CoMn11AFc500(TPR) & 0 & 0 & 10 & 0.0034 \\
\hline CoAFp600 & 34 & 0.00116 & 61 & 0.0212 \\
\hline MnAFp600 & 100 & 0.034 * & 195 & $0.066^{*}$ \\
\hline
\end{tabular}

$\mathrm{H}_{2}$-TPD results for the cobalt-only catalysts are in agreement to those reported by Popova and Babenkova for thermal desorption of preadsorbed hydrogen on a-Co and b-Co prepared by formate decomposition in a hydrogen flow at 300,350 and $600{ }^{\circ} \mathrm{C}$, whereas hydrogen desorption was completed at $300{ }^{\circ} \mathrm{C}$ [24].

\subsection{TPD of Adsorbed $\mathrm{H}_{2} \mathrm{O}$}

Water adsorption was carried out at 25 and $300^{\circ} \mathrm{C}$. A characteristic feature of water adsorption at $300{ }^{\circ} \mathrm{C}$ over catalysts prepared by pyrolysis is the accompanying appearance of hydrogen in the gas phase indicative of reactive adsorption according to:

$$
\mathrm{Co}+\mathrm{H}_{2} \mathrm{O} \rightarrow \mathrm{Co}-(\mathrm{O})+\mathrm{H}_{2}
$$

TPD profiles of $\mathrm{H}_{2} \mathrm{O}$ and $\mathrm{H}_{2}$ after water adsorption at room temperature over pyrolyzed catalysts are shown in Figure $4 . \mathrm{H}_{2} \mathrm{O}$ profiles are characterized by a main peak with maximum at $90-100{ }^{\circ} \mathrm{C}$ followed by a broad descending feature up to $450{ }^{\circ} \mathrm{C}$. Increase of pyrolysis temperature leads to decrease of the amount of adsorbed water. This trend is analogous to what was found for $\mathrm{CO}_{2}$ adsorption (Section 2.1). The profiles of $\mathrm{H}_{2}$ during TPD after water adsorption at room temperature 
over pyrolyzed catalysts are also presented in Figure 4. Hydrogen desorption is observed mostly above $400{ }^{\circ} \mathrm{C}$ with CoMn11AFp 600 catalyst showing also minor hydrogen desorption at $60^{\circ} \mathrm{C}$. Since TPD profiles following $\mathrm{H}_{2}$ adsorption are characterized by hydrogen peaks in the $400-600{ }^{\circ} \mathrm{C}$ range, it is not clear whether appearance of hydrogen in the gas phase is desorption or reaction limited. However, taking into account that water decomposition does take place at $300^{\circ} \mathrm{C}$, it is most probable that the profile of hydrogen is desorption limited. In addition, the absence of hydrogen in the low-temperature range implies that adsorbed water decomposition takes place at temperatures higher than $\sim 150{ }^{\circ} \mathrm{C}$. The amount of produced hydrogen during $\mathrm{H}_{2} \mathrm{O}-\mathrm{TPD}$ was $0.2-0.3 \mathrm{mmol} \cdot \mathrm{g}^{-1}$ while the amount of desorbed hydrogen after its adsorption at room temperature was $0.17-0.33 \mathrm{mmol} \cdot \mathrm{g}^{-1}$. This implies that the extent of adsorbed water decomposition is related to the number of surface centers available for adsorption of produced $\mathrm{H}_{2}$.

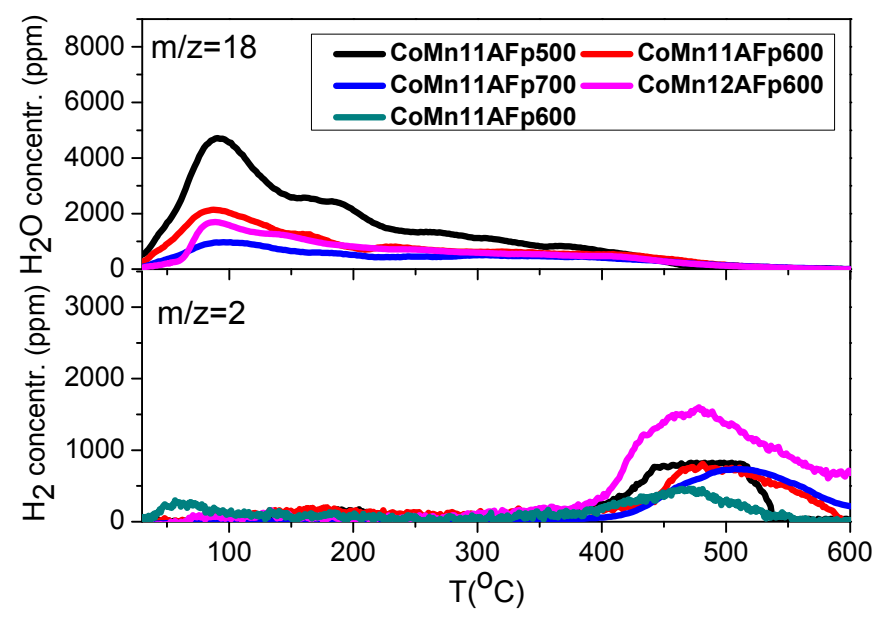

Figure 4. TPD profiles of $\mathrm{H}_{2} \mathrm{O}$ and $\mathrm{H}_{2}$ after water adsorption at $25^{\circ} \mathrm{C}$ over pyrolyzed catalysts.

Water adsorption at $300^{\circ} \mathrm{C}$ was accompanied by gaseous $\mathrm{H}_{2}$ production for all pyrolyzed catalysts with the exception of MnAFp600. TPD profiles of $\mathrm{H}_{2} \mathrm{O}$ and $\mathrm{H}_{2}$ after water adsorption at $300{ }^{\circ} \mathrm{C}$ over pyrolyzed catalysts are shown in Figure 5. TPD profiles of water consist of a main peak at $60-100{ }^{\circ} \mathrm{C}$ followed by a tail up to $500^{\circ} \mathrm{C}$. The profiles of hydrogen during TPD are quite broad and they show measurable desorption of hydrogen at the whole temperature range from 30 to $600{ }^{\circ} \mathrm{C}$. These are in general agreement to TPD profiles obtained following adsorption of hydrogen at $300^{\circ} \mathrm{C}$.

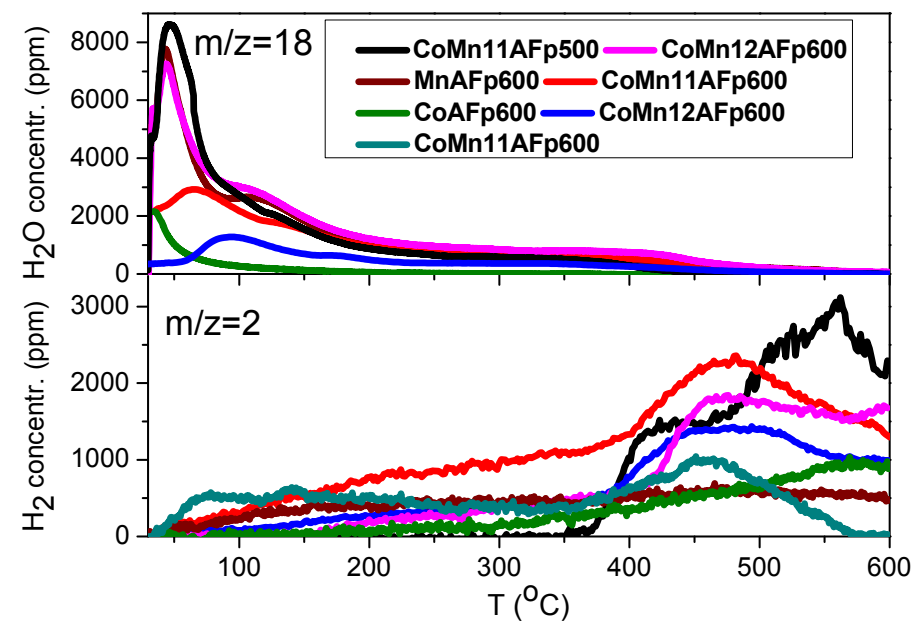

Figure 5. TPD profiles of $\mathrm{H}_{2} \mathrm{O}$ and $\mathrm{H}_{2}$ after water adsorption at $300{ }^{\circ} \mathrm{C}$ over pyrolyzed catalysts. 
Quantitative results of the total adsorbed water $\left(\mathrm{mmol} \cdot \mathrm{g}^{-1}\right.$ ) at $300^{\circ} \mathrm{C}$ (sum of water absorbed at $300{ }^{\circ} \mathrm{C}$ and during cooling to RT), hydrogen produced during $\mathrm{H}_{2} \mathrm{O}$ adsorption, and subsequent TPD as a function of catalyst content in Mn are given in Figure 6a,b. The total adsorbed water is four times higher on MnAFp600 than on CoAF600, although this difference is mostly due to water adsorbed during cooling. The highest amount of water adsorption is, however, observed over the Co-Mn catalysts. In an analogous manner, the amount of formed $\mathrm{H}_{2}$, i.e., the sum of hydrogen produced during adsorption and desorbed during TPD, is considerably higher over the Co-Mn catalysts compared to the cobalt-only catalyst and especially to the Mn-only sample.

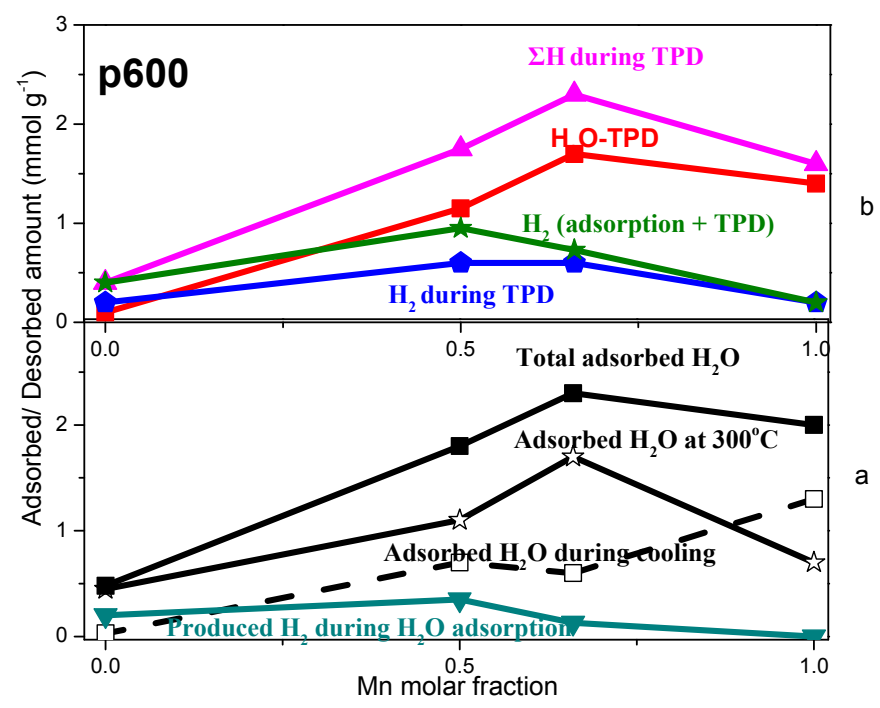

Figure 6. (a) Total absorbed $\mathrm{H}_{2} \mathrm{O}$ at $300{ }^{\circ} \mathrm{C}$ and $\mathrm{H}_{2}$ produced during water adsorption; and (b) $\mathrm{H}_{2} \mathrm{O}$ and $\mathrm{H}_{2}$ desorbed during TPD from CoAF, MnAF, CoMn11AF and CoMn12AF pyrolyzed at $600{ }^{\circ} \mathrm{C}$.

The CoAFp600 catalyst contains $11.6 \mathrm{mmol} \mathrm{Co} \cdot \mathrm{g}^{-1}$ and produced $0.4 \mathrm{mmol} \mathrm{H}_{2} \cdot \mathrm{g}^{-1}$ during water adsorption and TPD. Assuming one adsorbed hydrogen atom per surface cobalt atom, the resulting $\mathrm{H} / \mathrm{Co}$ ratio is 0.069 . The corresponding $\mathrm{H} / \mathrm{Co}$ ratio for hydrogen adsorption at $300^{\circ} \mathrm{C}$ is 0.021 (Table 1 ). In the case of the CoMn11AFp600 catalyst, the total amount of hydrogen was $0.8 \mathrm{mmol} \cdot \mathrm{g}^{-1}$, which compares well with the amount of hydrogen adsorbed during hydrogen adsorption $\left(0.66 \mathrm{mmol} \cdot \mathrm{g}^{-1}\right)$.

The effect of pyrolysis temperature of the CoMn11AF catalyst on adsorbed/desorbed water and $\mathrm{H}_{2}$ amounts is presented in Figure 7a,b, respectively. It can be observed that although the amount of total adsorbed water does not change appreciably with variation of pyrolysis temperature, there are changes in the "strength" of water adsorption. Thus, the amount of water desorbed during TPD decreases, because there is an increase in the amount of weakly adsorbed water, which desorbs already at room temperature before initiation of the TPD run. Similarly, the amount of water adsorbing during cooling decreases and the amount of water adsorbing at $300{ }^{\circ} \mathrm{C}$ increases with increase of pyrolysis temperature. This also relates to the fact that the extent of cobalt reduction increases with increase of pyrolysis temperature.

The effect of catalyst activation procedure on quantitative behavior of water adsorption is presented in Figure 8. Three catalysts are compared, all activated at $500{ }^{\circ} \mathrm{C}$ : CoMn11AFp500 prepared by pyrolysis, CoMn11AFc500(AIR) prepared by oxidation of the precursor and CoMn11AFc500(TPR) prepared from CoMn11AFc500(AIR) by subsequent reduction by $\mathrm{H}_{2}$ up to $600{ }^{\circ} \mathrm{C}$. The two latter catalysts adsorb significantly less water than CoMn11AFp500 and, in addition, they produce almost no hydrogen during exposure to water at $300^{\circ} \mathrm{C}$. 


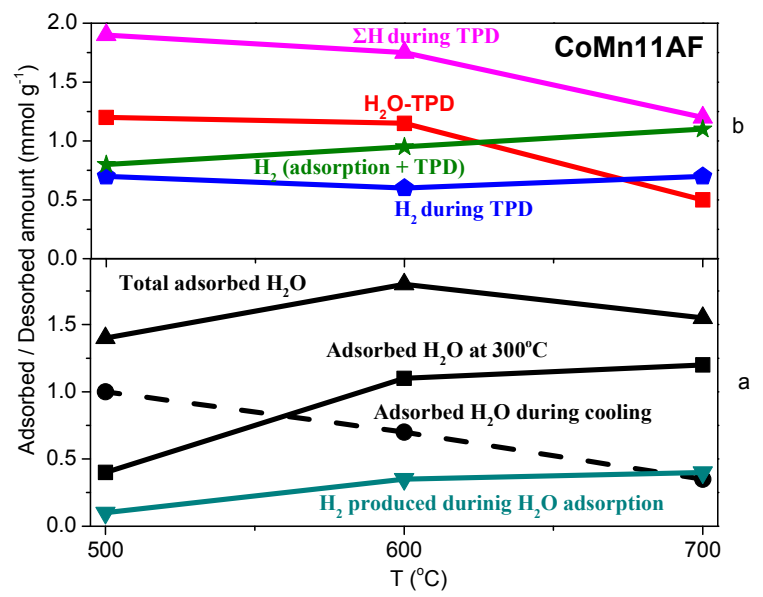

Figure 7. (a) Total absorbed $\mathrm{H}_{2} \mathrm{O}$ at $300{ }^{\circ} \mathrm{C}$ and $\mathrm{H}_{2}$ produced during water adsorption; and (b) $\mathrm{H}_{2} \mathrm{O}$ desorbed and $\mathrm{H}_{2}$ producing during TPD. CoMn11AFp $i$ with $i=500,600,700{ }^{\circ} \mathrm{C}$.

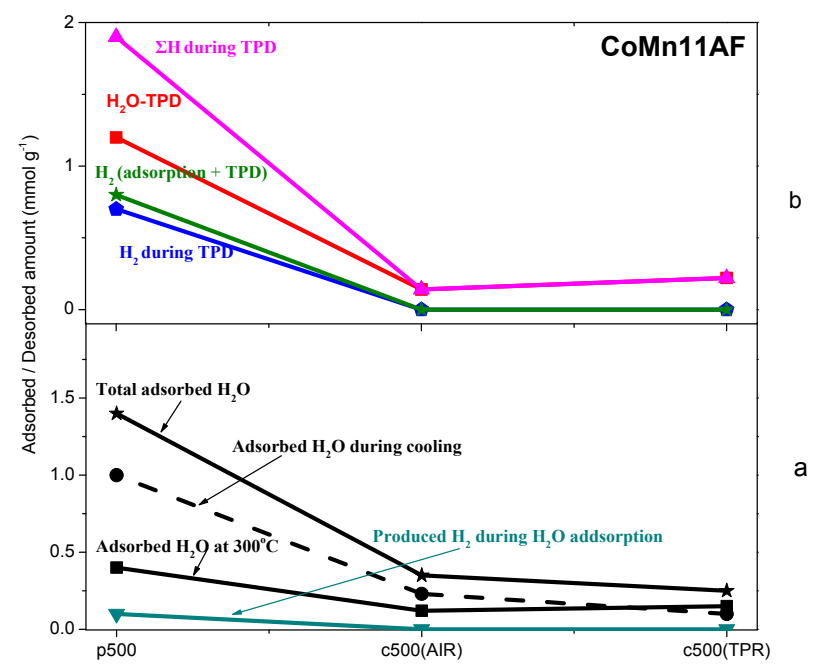

Figure 8. (a) Total absorbed $\mathrm{H}_{2} \mathrm{O}$ at $300{ }^{\circ} \mathrm{C}$ and $\mathrm{H}_{2}$ produced during water adsorption; and (b) $\mathrm{H}_{2} \mathrm{O}$ desorbed and $\mathrm{H}_{2}$ producing during TPD from CoMn11AFc500, CoMn11AFc500(AIR) and CoMn11AFc500(TPR).

\subsection{TPD of Adsorbed $\mathrm{CH}_{3} \mathrm{OH}$}

$\mathrm{CH}_{3} \mathrm{OH}, \mathrm{CO}, \mathrm{H}_{2}, \mathrm{CO}_{2}$ and $\mathrm{H}_{2} \mathrm{O}$ profiles during $\mathrm{CH}_{3} \mathrm{OH}$-TPD for CoMn11F samples pyrolyzed at 500 or $700{ }^{\circ} \mathrm{C}$ are shown in Figure 9a,b, respectively. Dashed lines in Figure 9a represent $\mathrm{CO}_{2}$, $\mathrm{H}_{2}, \mathrm{CO}$ and $\mathrm{H}_{2} \mathrm{O}$ production during the blank experiment (without prior methanol adsorption). The appearance of these molecules is due to residual pyrolysis of the fumarate precursor. TPD profiles following adsorption of methanol at room temperature indicated the presence of $\mathrm{CO}, \mathrm{CO}_{2}, \mathrm{H}_{2}$ and $\mathrm{H}_{2} \mathrm{O}$ in addition to methanol. Methanol desorption profiles are composed of a main peak at $90{ }^{\circ} \mathrm{C}$ and a less intense second peak in the form of a shoulder at $160^{\circ} \mathrm{C}$. Methanol desorption is completed at $300^{\circ} \mathrm{C}$ for CoMn11AFp500 and at $210^{\circ} \mathrm{C}$ for CoMn11AFp700. At the same time, methanol decomposition to $\mathrm{CO}$ and $\mathrm{H}_{2}$ takes place above $150{ }^{\circ} \mathrm{C}$ for both catalysts. The hydrogen peak is shifted by $\sim 10^{\circ} \mathrm{C}$ to the right compared to $\mathrm{CO}$ peak, probably due to readsorption effects. At the maximum $\mathrm{CO}$ production temperature $\left(230^{\circ} \mathrm{C}\right), \mathrm{CO}_{2}$ starts also appearing in the gas phase. One possible explanation for the production of $\mathrm{CO}_{2}$ is reaction of $\mathrm{CO}$ with catalyst surface oxygen. This hypothesis is supported by the fact that less $\mathrm{CO}_{2}$ is produced over the CoMn11AFp700 catalyst, which is in a more reduced state 
due to its activation at higher temperature. In addition, $\mathrm{CO}_{2}$ production is accompanied by water production (at least for CoMn11p500), which also indicates oxidation of hydrogen by surface oxygen. Another possibility is that (part of) $\mathrm{CO}_{2}$ is produced via the Boudouard reaction. This hypothesis cannot be checked by oxidation of surface carbon (also produced during Boudouard), since pyrolyzed catalysts already contain residual carbon in their structure. Judging from the fact that water production is minimal over the CoMn11AFp700, the occurrence of the Boudouard reaction cannot be disregarded.

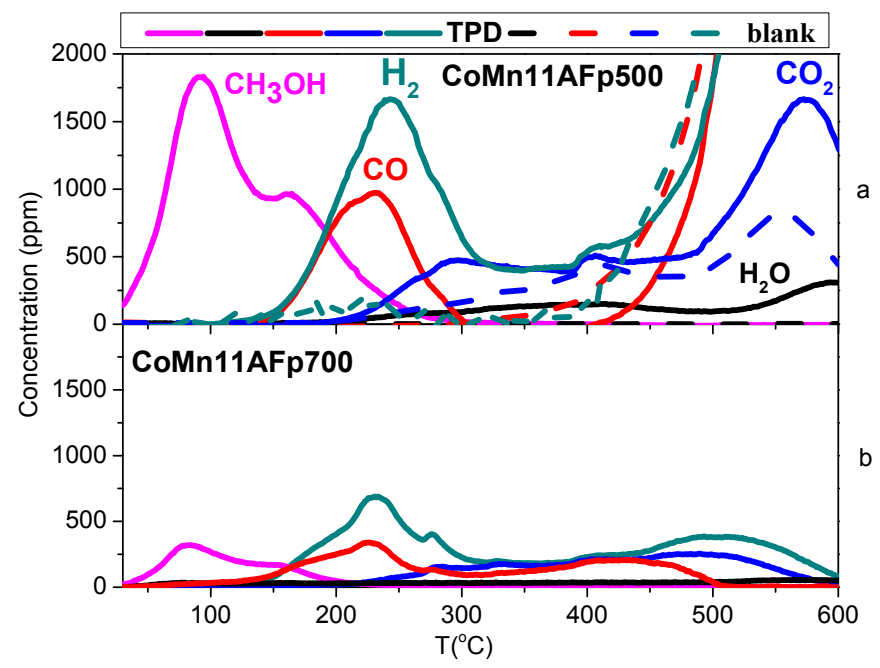

Figure 9. $\mathrm{CH}_{3} \mathrm{OH}-\mathrm{TPD}$ on CoMn11AFp500 and CoMn11AFp700.

$\mathrm{CH}_{3} \mathrm{OH}, \mathrm{CO}, \mathrm{H}_{2}, \mathrm{CO}_{2}$ and $\mathrm{H}_{2} \mathrm{O}$ profiles during $\mathrm{CH}_{3} \mathrm{OH}-\mathrm{TPD}$ from CoMn11AF and CoMn12AF catalysts prepared from pyrolysis at $600{ }^{\circ} \mathrm{C}$ are shown in Figure 10a,b, respectively. For both catalysts methanol is desorbed with a main peak at $90{ }^{\circ} \mathrm{C}$ and a tail extending up to $250^{\circ} \mathrm{C}$. The $\mathrm{CO}$ profile of CoMn11AFp600 includes two main peaks at 210 and $390{ }^{\circ} \mathrm{C}$ and is completed at $500{ }^{\circ} \mathrm{C}$. Decrease of cobalt content leads to $\mathrm{CO}$ production with a similar profile, but in this case its production extends even above $600{ }^{\circ} \mathrm{C}$. The hydrogen profile follows generally the CO profile. For both catalysts, $\mathrm{CO}_{2}$ production is also detected and is more intense on CoMn11AFp600. Overall, the profiles indicate the presence of more than one adsorbed species of methanol and have interference by $\mathrm{CO}_{2}$ readsorption effects (Figure 2b).

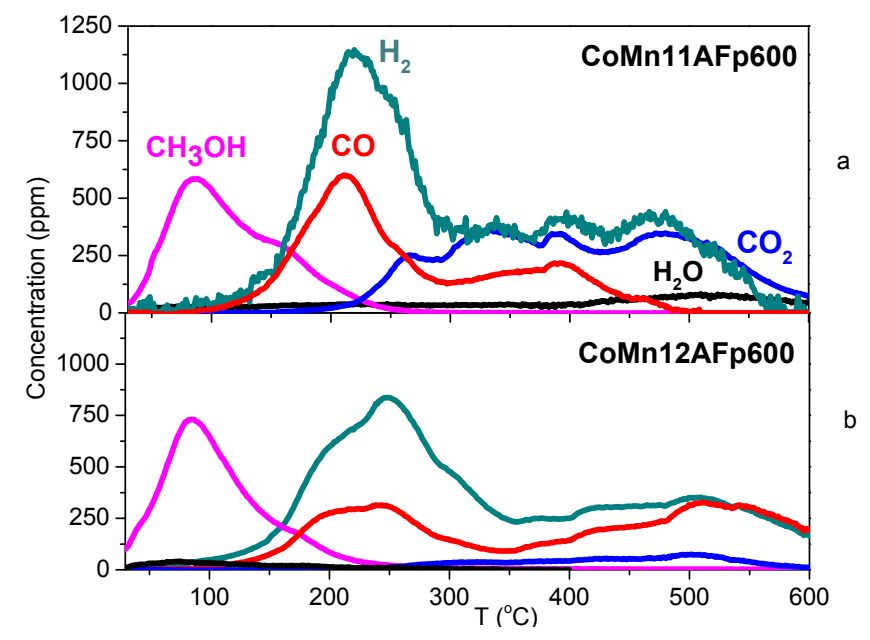

Figure 10. $\mathrm{CH}_{3} \mathrm{OH}-\mathrm{TPD}$ on CoMn11AFp600 and CoMn12AFp600. 
$\mathrm{CH}_{3} \mathrm{OH}, \mathrm{CO}, \mathrm{H}_{2}, \mathrm{CO}_{2}$ and $\mathrm{H}_{2} \mathrm{O}$ profiles during $\mathrm{CH}_{3} \mathrm{OH}-\mathrm{TPD}$ for the catalyst prepared by oxidative pretreatment (CoMn11AFc500(AIR)) or oxidation/reduction (CoMn11c500(TPR)) are shown in Figure 11. Methanol adsorbed on the oxidized catalyst mainly acts as a reducing agent during TPD. Hence, $\mathrm{CO}_{2}$ and $\mathrm{H}_{2} \mathrm{O}$ are produced from the oxidation of adsorbed methanol by surface oxygen. Oxidation of methanol takes place in the form of two peaks, indicative either of the presence of two different modes of adsorbed methanol or of stepwise reduction of the surface. The peaks of oxidation products, $\mathrm{CO}_{2}$ and $\mathrm{H}_{2} \mathrm{O}$, do not coincide evidently due to readsorption effects. The high temperature $\mathrm{CO}_{2}$ peak is accompanied by production of small quantities of $\mathrm{CO}$ and $\mathrm{H}_{2}$, which implies that active sites for methanol decomposition have been created only at that point (and not after the first $\mathrm{CO}_{2}$ peak). On the contrary, the TPD profile of CoMn11AFc500 (TPR) corresponds to decomposition of adsorbed methanol towards $\mathrm{CO}$ and $\mathrm{H}_{2}$ in the range of $150-250{ }^{\circ} \mathrm{C}$. The production of small amounts of $\mathrm{CO}_{2}$ can be attributed to additional surface reduction of the catalyst. Comparison of Figures 9-11 shows that the onset and the main peak of methanol decomposition to $\mathrm{CO}$ and $\mathrm{H}_{2}$ take place in the same temperature range for both the oxidized/reduced catalyst and all pyrolyzed catalysts. One important difference is that pyrolyzed catalysts contain additional states of adsorbed methanol which decompose at higher temperatures up to $500-600{ }^{\circ} \mathrm{C}$.

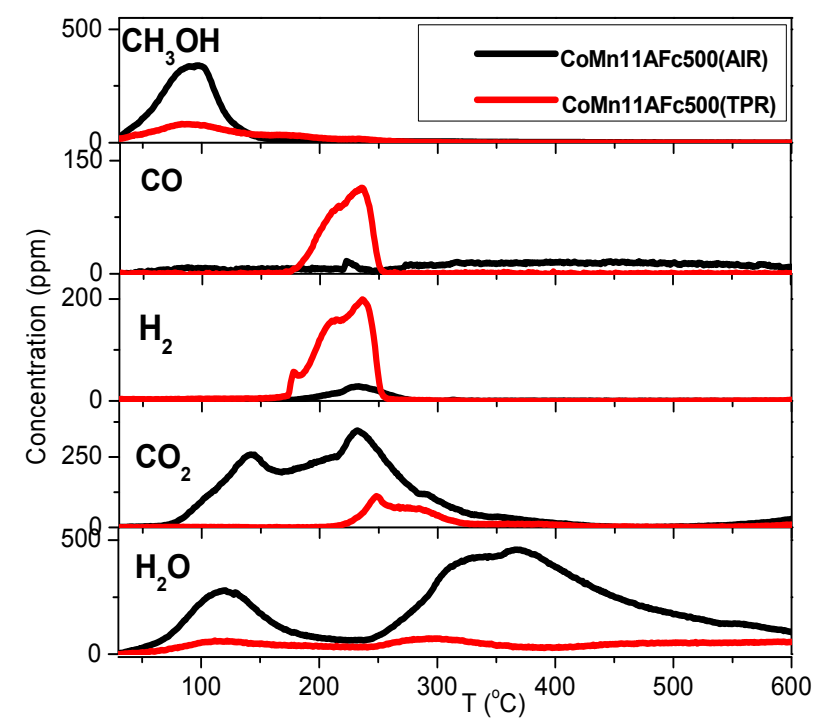

Figure 11. $\mathrm{CH}_{3} \mathrm{OH}-\mathrm{TPD}$ on CoMn11AFc500(AIR) and CoMn11AFc500(TPR).

The quantitative analysis of methanol adsorption and TPD experiments is presented in Figure 12. The amounts of adsorbed methanol are indicated with asterisks, while the amounts of desorbed $\mathrm{CH}_{3} \mathrm{OH}, \mathrm{CO}, \mathrm{CO}_{2}, \mathrm{H}_{2}$ and $\mathrm{H}_{2} \mathrm{O}$ during TPD are given in column form. The following observations can be made concerning Figure 12:

- With the exception of catalyst CoMn11AFp500, which adsorbs $1 \mathrm{mmol} \cdot \mathrm{g}^{-1}$, all catalysts adsorb methanol in the range of $0.2-0.5 \mathrm{mmol} \cdot \mathrm{g}^{-1}$. The lowest quantity is found over the oxidized/reduced sample.

- Less than half of adsorbed methanol desorbs molecularly.

- Increase of pyrolysis temperature and decrease of cobalt content lead to decrease of adsorbed methanol.

- The amounts of $\mathrm{CO}$ and $\mathrm{CO}_{2}$ produced during methanol TPD are 2-4 times higher over the pyrolyzed catalysts compared to those prepared via oxidation or oxidation/reduction.

- The oxygen mass balance between output and input shows a surplus indicating that adsorbed methanol acts as a reducing agent scavenging lattice oxygen from the catalysts. The amount of 
adsorbed methanol that gets oxidized towards $\mathrm{CO}_{2}$ and $\mathrm{H}_{2} \mathrm{O}$ depends on the oxidation state of the catalyst surface.

- The carbon mass balance is overall satisfied (error $<10 \%$ ) with the exception of the CoMn11AFp500 catalyst, because its reported values correspond to temperatures below $400{ }^{\circ} \mathrm{C}$ (at higher temperatures interference from residual pyrolysis does not allow for reliable measurement).

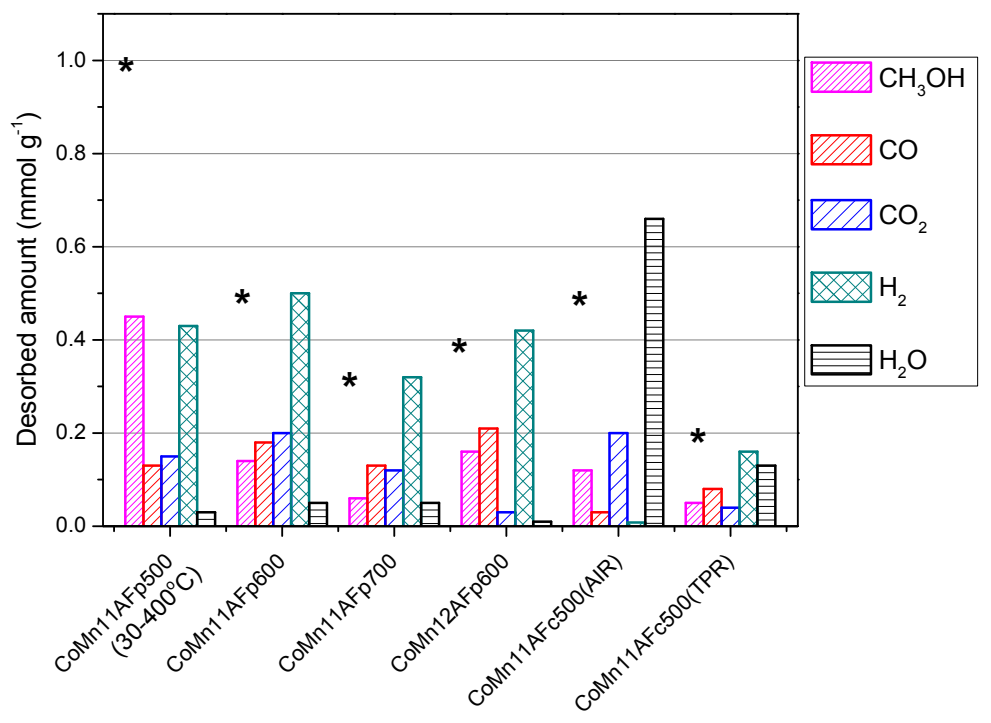

Figure 12. Desorbed amounts of $\mathrm{CH}_{3} \mathrm{OH}, \mathrm{CO}, \mathrm{CO}_{2}, \mathrm{H}_{2}$ and $\mathrm{H}_{2} \mathrm{O}$ during TPD after $\mathrm{CH}_{3} \mathrm{OH}$ adsorption. Adsorbed amount of methanol is shown with asterisks $\left({ }^{*}\right)$.

\subsection{Discussion}

Application of the catalysts examined in the present work in methanol steam reforming has shown that the catalysts obtained via pyrolysis are more active than those prepared via oxidative pretreatment [1,2]. The former are already in reduced state exemplified by the presence of metallic cobalt and a mixed $\mathrm{Co}_{x} \mathrm{Mn}_{1-x} \mathrm{O}$ phase, while the latter consist initially of a mixed Co-Mn spinel oxide phase. When exposed to the reforming reaction mixture, however, the spinel oxide phase gets gradually reduced and the catalyst becomes activated. It is understandable that surface reduction of the spinel phase is a prerequisite for switching on the catalytic function. The findings of the present work during TPD of methanol indicate that adsorbed methanol acts as the reduction agent and the preoxidized catalyst is indeed initially inactive in methanol decomposition (Figure 11). On the other hand, all pyrolyzed catalysts, as well as the oxidized/reduced catalyst, are active in the decomposition of preadsorbed methanol towards $\mathrm{CO}$ as well as $\mathrm{CO}_{2}$. The appearance of $\mathrm{CO}_{2}$ takes place at higher temperatures than $\mathrm{CO}$ and its profile is matched well by the profile of coproduced $\mathrm{H}_{2}$ (Figures 9 and 10). This implies that both $\mathrm{CO}_{2}$ and $\mathrm{H}_{2}$ originate from a common surface species, which is most probably formate. At this point, it would be interesting to compare the observed behavior of cobalt catalysts in methanol-TPD with the one of copper catalysts and, more specifically, $\mathrm{CuO} / \mathrm{Al}_{2} \mathrm{O}_{3}$ [33]. The TPD profile from $\mathrm{CuO} / \mathrm{Al}_{2} \mathrm{O}_{3}$ contains minor amounts of methanol $\left(170{ }^{\circ} \mathrm{C}\right)$ and production of $\mathrm{CO}_{2}$ and $\mathrm{H}_{2}$ with peak at $200-250^{\circ} \mathrm{C}$. Small amounts of $\mathrm{HCOOH}$ are also produced in the same temperature range. $\mathrm{CO}$ is observed at higher temperatures with peak at $350{ }^{\circ} \mathrm{C}$. Therefore, the main difference in the function of cobalt and copper catalysts is that $\mathrm{CuO}$ forms surface formate from adsorbed methanol, which decomposes at relatively low temperature to $\mathrm{CO}_{2}$ and hydrogen. The observed $\mathrm{CO}$ at higher temperatures may be attributed to the reverse water-gas shift reaction. The cobalt catalysts of the present work, on the other hand, produce $\mathrm{CO}$ and $\mathrm{H}_{2}$ at $200-250{ }^{\circ} \mathrm{C}$, while $\mathrm{CO}_{2}$ and $\mathrm{H}_{2}$ production from formate decomposition is observed at much higher temperatures. These results exemplify nicely the superiority of copper versus cobalt in steam reforming of methanol: copper creates formate species 
which decompose at low temperatures to $\mathrm{CO}_{2}$ and $\mathrm{H}_{2}$, while cobalt decomposes methanol to $\mathrm{CO}$ and $\mathrm{H}_{2}$ and the created formate species are stable so that they act rather as spectators occupying a fraction of the active sites [34].

The higher activity of pyrolyzed catalysts can be attributed mainly to their higher number density of active sites since peak temperatures of CO during TPD after methanol adsorption are similar in pyrolyzed and oxidized/reduced catalysts. During pyrolysis of the fumarate precursors, residual carbon is left behind and helps stabilize cobalt and $\mathrm{MnO}$ crystallites against extensive sintering. The resulting specific surface area of pyrolyzed catalysts is thus approximately one order of magnitude higher than the one of spinel oxide samples [1]. The higher available area for adsorption has been confirmed for water (Figure 8) and $\mathrm{CO}_{2}$ (Figure 2) adsorption, whereas pyrolyzed samples adsorb up to one order of magnitude more water or $\mathrm{CO}_{2}$ per unit weight. This applies to a lesser extent for methanol adsorption, whereas pyrolyzed samples adsorb up to 5 times more methanol. It is understandable that a certain fraction of these adsorbed molecules on pyrolyzed catalysts may reside on the carbonaceous support, whose surface composition in terms of oxygen content is strongly dependent on pyrolysis temperature. This may explain the observed variations in the adsorbed amounts of water, methanol and $\mathrm{CO}_{2}$ as a function of pyrolysis temperature, which causes no change in the BET surface area otherwise. Comparison of relative amounts of adsorbed hydrogen and methanol on pyrolyzed and oxidized/reduced catalysts shows considerable discrepancies. Using hydrogen adsorption as a measure of cobalt dispersion and hence of active sites would lead to a wrong conclusion regarding differences among the various samples as related to activity in methanol reforming. In this respect, methanol is a more suitable probe, since it is the molecule of interest in the target reaction. Following this train of thought, one should further consider not the total amount of adsorbed methanol, but rather the amount of irreversibly adsorbed methanol that decomposes during heating. In this respect, the concentration of active sites in pyrolyzed catalysts is smaller than the one expected if one takes BET surface area or the amount of adsorbed hydrogen as indicators.

Concerning the role of water, it has been found in the present work that the catalysts are effective in dissociating the water molecule at temperatures of interest for the reforming reaction getting themselves oxidized in the process. The extent of water adsorption and dissociation is directly related to available sites responding to hydrogen adsorption ( $\mathrm{H}_{2}-\mathrm{TPD}$ experiments). Although one could envisage, based on this finding, methanol reforming taking place through a surface reduction-oxidation mechanism, i.e., surface reduction by methanol leading to $\mathrm{CO}_{2}$ and $\mathrm{H}_{2} \mathrm{O}$ production followed by surface reoxidation by water leading to hydrogen production, this does not appear to be the case. Indeed, the product distribution during methanol reforming over all cobalt catalysts examined indicates a mechanism comprising methanol decomposition and the water-gas shift reaction and CO selectivity is higher or at best equal to the one predicted by thermodynamic equilibrium.

\section{Experimental Section}

\subsection{Catalyst Preparation}

The precursor compounds for catalyst synthesis were mixed fumarate salts of cobalt and manganese, which were prepared by mixing aqueous solutions of cobalt and manganese acetate with a solution of fumaric acid in ethanol followed by drying at $120^{\circ} \mathrm{C}$. The corresponding catalysts were prepared by pyrolysis of the salts under inert gas with a linear heating rate of $5^{\circ} \mathrm{C} / \mathrm{min}$ to the target temperature, 500,600 or $700^{\circ} \mathrm{C}$, soak for $5 \mathrm{~min}$ and cooling down to adsorption temperature. The pyrolyzed catalysts are named CoMn $1 x$ AFpTTT, with TTT being the pyrolysis temperature and $1 x$ ( $x=1$ or 2 ) being the $\mathrm{Co} / \mathrm{Mn}$ atomic ratio. For example, the CoMn11AFp600 catalyst has a Co/Mn atomic ratio of $1 / 1$ and has been prepared by pyrolysis at $600{ }^{\circ} \mathrm{C}$. Samples were also prepared via oxidative treatment of the salts at $500{ }^{\circ} \mathrm{C}$ for $2 \mathrm{~h}$ for comparison purposes (named CoMn11AFc500). Calcined catalysts that had been reduced before adsorption are named CoMn11AFc500 (TPR). 


\subsection{Catalyst Characterization}

Catalysts were characterized by nitrogen physisorption (BET), $\mathrm{H}_{2}-\mathrm{TPR}, \mathrm{CH}_{3} \mathrm{OH}$-TPR and in-situ $X R D$. Characterization results have been reported in $[1,2]$.

\subsection{TPD Experiments}

Temperature-programmed desorption (TPD) of pre-adsorbed $\mathrm{CH}_{3} \mathrm{OH}, \mathrm{H}_{2} \mathrm{O}, \mathrm{H}_{2}, \mathrm{CO}_{2}$ and $\mathrm{CO}$ at room temperature were performed. TPD of pre-adsorbed $\mathrm{H}_{2} \mathrm{O}$ and $\mathrm{H}_{2}$ at $300{ }^{\circ} \mathrm{C}$ were performed also. Temperature Programmed Desorption (TPD) experiments were carried out at atmospheric pressure in a fixed-bed reactor system with two independent gas lines equipped with mass flow controllers (Aera $\mathrm{GmbH}$, Kirchheim, Germany). A mass spectrometer (Omnistar/Pfeiffer Vacuum, Asslar, Germany) was used for on-line monitoring of effluent gases. Prior to each $\mathrm{CO}$ or $\mathrm{CO}_{2}$ adsorption experiment, the calcined catalysts were reduced by $3 \% \mathrm{H}_{2} / \mathrm{He}$ mixture at $400{ }^{\circ} \mathrm{C}$ for $20 \mathrm{~min}$ with a linear heating rate of $5{ }^{\circ} \mathrm{C} \cdot \mathrm{min}^{-1}$. For all the other molecules examined reduction of calcined catalysts was performed by $3 \% \mathrm{H}_{2} / \mathrm{He}$ mixture at $600{ }^{\circ} \mathrm{C}$ for $30 \mathrm{~min}$. For all molecules whose adsorption was studied at room temperature following completion of the adsorption, indicated by stable signals in the mass spectrometer, the reactor was purged with pure He until all signals met their baselines. Then, the TPD run was started under a helium flow of $50 \mathrm{~cm}^{3} \cdot \mathrm{min}^{-1}$ with a heating rate of $10{ }^{\circ} \mathrm{C} \cdot \mathrm{min}^{-1}$. For all molecules whose adsorption was studied at $300{ }^{\circ} \mathrm{C}$, cooling from adsorption temperature to $30^{\circ} \mathrm{C}$ was performed in the presence of the same gaseous flow. After cooling, the reactor was purged with $50 \mathrm{~cm}^{3} \cdot \mathrm{min}^{-1} \mathrm{He}$ and TPD was started as soon as the signals had been stabilized. For all catalysts, blank experiments were also performed. Adsorption of $\mathrm{CO}$ and $\mathrm{CO}_{2}$ was carried out under a flow of $1.1 \% \mathrm{CO} / \mathrm{He}\left(50 \mathrm{~cm}^{3} \cdot \mathrm{min}^{-1}\right)$ or $1.1 \% \mathrm{CO}_{2} / \mathrm{He}\left(50 \mathrm{~cm}^{3} \cdot \mathrm{min}^{-1}\right)$ mixture, respectively. Hydrogen adsorption was performed under pure hydrogen flow of $20 \mathrm{~cm}^{3} \cdot \mathrm{min}^{-1}$ for $10 \mathrm{~min}$. Water adsorption was carried out using a $5400 \mathrm{ppm} \mathrm{H}_{2} \mathrm{O} / \mathrm{He}$ mixture $\left(50 \mathrm{~cm}^{3} \cdot \mathrm{min}^{-1}\right)$. Methanol adsorption was carried out using a 17,000 ppm $\mathrm{CH}_{3} \mathrm{OH} / \mathrm{He}$ mixture. The following masses were recorded in the mass spectrometer during all TPD experiments: $18\left(\mathrm{H}_{2} \mathrm{O}\right), 28(\mathrm{CO}), 44\left(\mathrm{CO}_{2}\right), 31$ and $32\left(\mathrm{CH}_{3} \mathrm{OH}\right), 15\left(\mathrm{CH}_{4}\right)$, 29 and $30(\mathrm{HCHO}), 45\left(\mathrm{CH}_{3} \mathrm{OCH}_{3}\right)$ and $49(\mathrm{HCOOH})$.

\section{Conclusions}

The employment of TPD in order to investigate the interaction of $\mathrm{CO}, \mathrm{CO}_{2}, \mathrm{H}_{2}, \mathrm{H}_{2} \mathrm{O}$ and $\mathrm{CH}_{3} \mathrm{OH}$ with cobalt catalysts prepared from cobalt-manganese fumarate precursors via pyrolysis or oxidation has led to the following findings:

- Adsorption of $\mathrm{CO}$ and $\mathrm{H}_{2}$ is activated. Although activated hydrogen adsorption on cobalt is well established, activated adsorption of $\mathrm{CO}$ has not been reported previously.

- Hydrogen appears to adsorb both on cobalt and MnO components. Taking into account literature results concerning cobalt and $\mathrm{MnO}$ and results of the present work concerning cobalt, $\mathrm{MnO}$ and Co-MnO samples, it is inferred that hydrogen desorbing below $250{ }^{\circ} \mathrm{C}$ originates from cobalt crystallites, hydrogen desorbing above $500^{\circ} \mathrm{C}$ originates from $\mathrm{MnO}$, while hydrogen desorbing in the intermediate temperature range $\left(250-500^{\circ} \mathrm{C}\right)$ probably originates from sites created at the interface of $\mathrm{Co}$ and $\mathrm{MnO}$ or from a mixed reduced oxide phase.

- Water adsorption is dissociative at an adsorption temperature of $300^{\circ} \mathrm{C}$, but not at $25^{\circ} \mathrm{C}$, leading to surface oxidation of the catalyst. Hydrogen produced from water dissociation remains partially adsorbed on the catalyst surface confirming that part of hydrogen is quite strongly bound on the catalysts.

- Reaction paths of adsorbed methanol during TPD include decomposition to $\mathrm{CO}$ and $\mathrm{H}_{2}$, as well as creation of rather stable surface formates, which decompose at higher temperatures to $\mathrm{CO}_{2}$ and $\mathrm{H}_{2}$. Adsorbed methanol acts as a reducing agent during TPD leading to catalyst reduction. 
- Differences of the pyrolyzed and oxidized/reduced catalysts appear to be mainly in the number density of active sites, which, however, is not directly analogous to differences in specific surface area.

Acknowledgments: This work was carried out in the frame of the ACENET project "Hydrogen from bio-alcohols: An efficient route for hydrogen production via novel reforming catalysts" (ACE.07.009). The authors acknowledge funding from the General Secretariat for Research and Technology of the Ministry of Education, Lifelong Learning and Religious Affairs (Greece).

Author Contributions: E.P. and T.I. conceived and designed the experiments; E.P. performed the experiments; E.P. and T.I. analyzed the data; T.I. wrote the paper.

Conflicts of Interest: The authors declare no conflict of interest.

\section{References}

1. Papadopoulou, E.; Ioannides, T. Steam reforming of methanol over cobalt catalysts: effect of cobalt oxidation state. Int. J. Hydrogen Energy 2015, 40, 5251-5255. [CrossRef]

2. Papadopoulou, E.; Delimaris, D.; Denis, A.; Machocki, A.; Ioannides, T. Alcohol reforming on cobalt-based catalysts prepared from organic salt precursors. Int. J. Hydrogen Energy 2012, 37, 16375-16381. [CrossRef]

3. Yong, S.T.; Ooi, C.W.; Chai, S.P.; Wu, X.S. Review of methanol reforming-Cu-based catalysts, surface reaction mechanisms, and reaction schemes. Int. J. Hydrogen Energy 2013, 38, 9541-9552. [CrossRef]

4. Sá, S.; Silva, H.; Brandão, L.; Sousa, J.M.; Mendes, A. Catalysts for methanol steam reforming-A review. Appl. Catal. B 2010, 99, 43-57. [CrossRef]

5. Palo, D.R.; Dagle, R.A.; Holladay, J.D. Methanol Steam Reforming for Hydrogen Production. Chem. Rev. 2007, 107, 3992-4021. [CrossRef] [PubMed]

6. Agrell, J.; Birgersson, H.; Boutonnet, M.; Melián-Cabrera, I.; Navarro, R.M.; Fierro, J.L.G. Production of hydrogen from methanol over $\mathrm{Cu} / \mathrm{ZnO}$ catalysts promoted by $\mathrm{ZrO}_{2}$ and $\mathrm{Al}_{2} \mathrm{O}_{3}$. J. Catal. 2003, 219, 389-403. [CrossRef]

7. De Wild, P.J.; Verhaak, M.J.F.M. Catalytic production of hydrogen from methanol. Catal. Today 2000, 60, 3-10. [CrossRef]

8. Matter, P.H.; Braden, D.J.; Ozkan, U.S. Steam reforming of methanol to $\mathrm{H}_{2}$ over nonreduced $\mathrm{Zr}$-containing $\mathrm{CuO} / \mathrm{ZnO}$ catalysts. J. Catal. 2004, 223, 340-351. [CrossRef]

9. Tartakovsky, L.; Baibikov, V.; Veinblat, M. Comparative Performance Analysis of SI Engine Fed by Ethanol and Methanol Reforming Products. SAE Tech. Pap. 2013. [CrossRef]

10. Habermehl-Cwirzen, K. An Insight: Studies of Atomic and Molecular Adsorption on Co(0001); Helsinki University of Technology: Helsinki, Finland, 2006.

11. Blyholder, G.; Wyatt, W.V. Infrared spectra and structures of some C,H,O compounds adsorbed on silica-supported iron, cobalt, and nickel. J. Phys. Chem. 1966, 70, 1745-1750. [CrossRef]

12. Natile, M.M.; Glisenti, A. Study of surface reactivity of cobalt oxides: interaction with methanol. Chem. Mater. 2002, 14, 3090-3099. [CrossRef]

13. Grellner, F.; Klingenberg, B.; Borgmann, D.; Wedler, G. Electron spectroscopic study of the interaction of oxygen with $\mathrm{Co}(1120)$ and of coadsorption with water. J. Electron Spectrosc. 1995, 71, 107-115. [CrossRef]

14. Heras, J.M.; Papp, H.; Spiess, W. Face specificity of the $\mathrm{H}_{2} \mathrm{O}$ adsorption and decomposition on Co surfaces: A LEED, UPS, sp and TPD study. Surf. Sci. 1982, 117, 590-604. [CrossRef]

15. Reuel, R.C.; Bartholomew, C.H. The stoichiometries of $\mathrm{H}_{2}$ and $\mathrm{CO}$ adsorptions on cobalt: Effects of support and preparation. J. Catal. 1984, 85, 63-77. [CrossRef]

16. Bartholomew, C.H.; Reuel, R.C. Cobalt-support interactions: Their effects on adsorption and CO hydrogenation activity and selectivity properties. Ind. Eng. Chem. Prod. Res. Dev. 1985, 24, 56-61. [CrossRef]

17. Zowtiak, J.M.; Bartholomew, C.H. The kinetics of $\mathrm{H}_{2}$ adsorption on and desorption from cobalt and the effects of support thereon. J. Catal. 1983, 83, 107-120. [CrossRef]

18. Tejuca, L.G.; Bell, A.T.; Fierro, J.L.G.; Pena, M.A. Surface behavior of reduced $\mathrm{LaCoO}_{3}$ as studied by TPD of $\mathrm{CO}, \mathrm{CO}_{2}$ and $\mathrm{H}_{2}$ probes and by XPS. Appl. Surf. Sci. 1988, 31, 301-316. [CrossRef] 
19. Narayanan, S.; Unnikrishnan, R.P. Comparison of hydrogen adsorption and aniline hydrogenation over co-precipitated $\mathrm{Co} / \mathrm{Al}_{2} \mathrm{O}_{3}$ and $\mathrm{Ni} / \mathrm{Al}_{2} \mathrm{O}_{3}$ catalysts. J. Chem. Soc. Faraday Trans. 1997, 93, 2009-2013. [CrossRef]

20. Sakka, Y.; Ohno, S. Hydrogen desorption characteristics of composite Co-TiN nanoparticles. Appl. Surf. Sci. 1996, 100/101, 232-237. [CrossRef]

21. Soonq, Y.; Rao, V.U.S.; Zarochak, M.F.; Gormley, R.J.; Zhang, B. Temperature-programmed desorption study on manganese-iron catalysts. Appl. Catal. 1991, 78, 97-108. [CrossRef]

22. Gauthier, Y.; Schmidt, M.; Padovani, S.; Lundgren, E.; Bus, V.; Kresse, G.; Redinger, J.; Vagra, P. Adsorption sites and ligand effect for CO on an alloy surface: A direct view. Phys. Rev. Lett. 2001, 87, 036103. [CrossRef] [PubMed]

23. Jiang, M.; Koizumi, N.; Ozaki, T.; Yamada, M. Adsorption properties of cobalt and cobalt-manganese catalysts studied by in situ diffuse reflectance FTIR using $\mathrm{CO}$ and $\mathrm{CO}+\mathrm{H}_{2}$ as probes. Appl. Catal. A 2001, 209, 59-70. [CrossRef]

24. Mohana Rao, K.; Scarano, D.; Spoto, G.; Zecchina, A. CO adsorption on cobalt particles supported on MgO: An IR investigation. Surf. Sci. 1988, 204, 319-330. [CrossRef]

25. Rostrup-Nielsen, J.R. Catalytic Steam Reforming. Catalysis 1984, 5, 1-117.

26. Baker, R.T.K.; Kim, M.S.; Chambers, A.; Park, C.; Rodriguez, N.M. The relationship between metal particle morphology and the structural characteristics of carbon deposits. Stud. Surf. Sci. Catal. 1997, 111, 99-109.

27. Ōya, A.; Ōtani, S. Catalytic graphitization of carbons by various metals. Carbon 1979, 17, 131-137. [CrossRef]

28. Budiman, A.W.; Song, S.A.; Chang, T.S.; Shin, C.H.; Choi, M.J. Dry Reforming of Methane Over Cobalt Catalysts: A Literature Review of Catalyst Development. Catal. Surv. Asia 2012, 16, 183-197. [CrossRef]

29. Tsakoumis, M.; Ronning, M.; Qyvind, B. Deactivation of cobalt based Fischer-Tropsch catalysts: A review. Catal. Today 2010, 154, 162-182. [CrossRef]

30. Bartholomew, C.H. Mechanisms of catalyst deactivation. Appl. Catal. A 2001, 21, 17-60. [CrossRef]

31. Bartholomew, C.H. Carbon Deposition in Steam Reforming and Methanation. Catal. Rev. Sci. Eng. 1982, 24, 67-112. [CrossRef]

32. Nakamura, J.; Tanaka, K.; Toyoshima, I. Reactivity of deposited carbon on Co- $\mathrm{Al}_{2} \mathrm{O}_{3}$ catalyst. J. Catal. 1987, 108, 55-62. [CrossRef]

33. Tagawa, T.; Pleizier, G.; Amenomiya, Y. Methanol synthesis from $\mathrm{CO}_{2}+\mathrm{H}_{2}$ : Characterization of catalysts by TPD. Appl. Catal. 1985, 18, 285-293. [CrossRef]

34. Meunier, F.C.; Reid, D.; Goguet, A.; Shekhtman, S.; Hardacre, C.; Burch, R.; Deng, W.; Flytzani-Stephanopoulos, M. Quantitative analysis of the reactivity of formate species seen by DRIFTS over a $\mathrm{Au} / \mathrm{Ce}(\mathrm{La}) \mathrm{O}_{2}$ water-gas shift catalyst: First unambiguous evidence of the minority role of formates as reaction intermediates. J. Catal. 2007, 247, 269-279.

(C) 2016 by the authors; licensee MDPI, Basel, Switzerland. This article is an open access article distributed under the terms and conditions of the Creative Commons by Attribution (CC-BY) license (http://creativecommons.org/licenses/by/4.0/). 